\title{
IDENTIFICAÇÃO DOS RECURSOS ESTRATÉGICOS GERADORES DE VANTAGEM COMPETITIVA: UM ESTUDO DE CASO NO SETOR RODOVIÁRIO
}

\author{
Gregório Bastos Neto ${ }^{1}$ \\ Isaias Ricardo Carraro ${ }^{2}$ \\ Simone Fonseca de Andrade ${ }^{3}$ \\ Guilherme Cunha Malafaia ${ }^{4}$
}

\section{Resumo}

Embora a abordagem do posicionamento estratégico seja a mais referenciada ao tratar-se de vantagem competitiva, autores chamam atenção para a Resource Based View, que valoriza recursos internos - físicos, financeiros, individuais, organizacionais. O modeloVRIO contribui para identificação desses recursos, analisando-os segundo seu valor, raridade, imitabilidade e organização. Utilizando-se o modelo VRIO, este estudo de caso objetivou identificar e analisar se recursos de novas plantas industriais de duas empresas do setor de implementos rodoferroviários contribuem para obtenção de vantagem competitiva. Identificou-se que, em uma das empresas, a vantagem decorre de recursos organizacionais, enquanto que na outra, provém de recursos físicos.

Palavras-chave: Recursos Estratégicos. Vantagem Competitiva. Setor Rodoviário.

\section{$* * *$}

1 Mestre, e-mail: gregoriobastosneto@ gmail.com

2 Mestre, e-mail: isaias.carraro@ gmail.com

3 Mestre, e-mail: simo.fandrade@ gmail.com

4 Doutor, e-mail: gcmalafaia@gmail.com *** 


\section{INTRODUÇÃO}

Num ambiente econômico e sociocultural cada vez mais integrado, o fenômeno da globalização reformula as noções de tempo e espaço, aproxima empresas e países, abrindo assim janelas de oportunidades. Porém, nesse contexto, a natureza complexa e imprevisível dos cenários impede um controle deliberado sobre o processo de obtenção de vantagens competitivas (LOBATO, 2003). Segundo Vasconcelos e Cyrino (2000), a vantagem competitiva decorre de níveis de desempenho econômico acima da média de mercado, em função das estratégias adotadas pelas organizações.

A vantagem competitiva de uma empresa depende das estratégias que adota,e a manutenção dessa vantagem está baseada em seu processo de criação de valor. A criação de valor acontece quando a empresa trabalha diferente de seus concorrentes, ou configurando sua cadeia de valor de forma similar à concorrência, porém com mais eficiência (JOIA; FERREIRA, 2005). Porter (1996) recomenda que as empresas entreguem mais valor a seus clientes ou criem um valor comparável a um custo mais baixo, ou ainda que adotem essas duas estratégias.

Na visão de Porter (1980,1985), a essência da formulação das estratégias é lidar com a competição.Para esse autor, o estado de competição em um segmento industrial depende de cinco forças básicas, que Porter reuniu em um modelo de análise, envolvendo (i) os concorrentes, (ii) os responsáveis por produtos substitutos, (iii) os fornecedores, (ix) os consumidores e (x) os potenciais entrantes no setor de atividades da empresa. Segundo o autor, o resultado coletivo desses elementos determina a vantagem potencial máxima de um setor industrial. A interpretação dessas cinco forças fez com que essa abordagem fosse também reconhecida como análise "de fora para dentro" ou "escola do posicionamento estratégico" (FLEURY; FLEURY, 2004).

Apesar da forte contribuição dessa abordagem analítica, de acordo com Wilk e Fensterseifer (2003), pesquisas recentes estão prestando maior atenção ao ambiente interno das empresas para explicar as diferenças de desempenho, perspectiva essa incorporada à Resource-Based View (RBV) ou, numa tradução livre para o português, Visão Baseada em Recursos (VBR), que é a abordagem teórica que orienta a presente investigação.

A RBV surgiu durante os anos 80 , como uma alternativa à abordagem de Porter (VASCONCELOS; CYRINO, 2000; FLEURY; FLEURY, 2004).

AtrAVÉS DE UMA ANÁLISE DOS

RECURSOS E COMPETÊNCIAS

INTERNAS DA EMPRESA, A RBV

IDENTIFICA OPORTUNIDADES

PARA OBTENÇÃO DE VANTAGEM

COMPETITIVA SUSTENTÁVEL,

CONFIRMANDO ASSIM SEU VIÉS

DE ANÁLISE DE DENTRO DA

INDÚSTRIA PARA FORA DELA.

Para Foss (1996), na perspectiva da RBV, a estratégia competitiva é a arte de criação, acumulação e utilização dos recursos, ao invés da construção de barreiras de entrada em face dos demais concorrentes nos segmentos-alvos de produto/mercado. 
Considerando a importância que a visão baseada em recursos vem tomando nos âmbitos acadêmico e organizacional, este artigo tem como objetivo analisar se os recursos estratégicos de novas plantas industriais para produtos frigoríficos das duas empresas líderes do setor de implementos rodoferroviários contribuem para a vantagem competitiva dessas empresas. Para isso, foi utilizado o Modelo VRIO (Value, Rarity, Imitability, Organization), proposto por Barney e Hesterly (2011), como estrutura teórico-conceitual para a análise de recursos estratégicos identificados em duas organizações.

Considerado o segundo maior exportador do continente americano, o Brasil conta com 1,3 mil empresas de implementos rodoviários, empregando mais de 83 mil pessoas, com faturamento em 2013 na ordem de R \$ 9,3 bilhões (SIMEFRE, 2014). A produção de reboques e semirreboques no Brasil, no ano de 2013, atingiu 174.400 unidades, sendo 5.400 destinadas a exportações (SIMEFRE, 2014). Conforme informações da Secretaria de Desenvolvimento ePromoção do Investimento (SDPI) do Estado do Rio Grande do Sul(RS), as empresas gaúchas produzem mais de $50 \%$ do total nacional nesse segmento, gerando 20.324 postos de trabalho no RS (SDPI, 2012).
As empresas que são foco desse estudo, chamadas empresa Alfa e empresa Beta, detêm juntas, mais de 70\% do market share, caracterizando-as como líderes do segmento de implementos rodoviários.

Do total da receita bruta da empresa Alfa, $35 \%$ referem-se ao produto furgão frigorífico, sendo que $80 \%$ desses são comercializados para o estado de Santa Catarina. Quanto à empresa Beta, os furgões representam $10 \%$ de sua receita bruta. Os furgões frigoríficos tiveram uma produção total no Brasil de 2530 unidades no ano de 2013 (ANFIR, 2014).

A pesquisa que será apresentada através deste artigo parte de um referencial teórico que aborda o conceito de RBV e o Modelo VRIO. Posteriormente, são expostos os procedimentos metodológicos utilizados na coleta de dados e informações e que possibilitaram uma análise das vantagens competitivas adquiridas pelas empresas objetos deste estudo. Após, na análise dos resultados, são apresentados os recursos identificados em cada empresa, permitindo evidenciar algumas conclusões, expostas ao final do trabalho.

\section{RBV E ANÁLISE DO MODELO VRIO NO SETOR DE IMPLEMENTOS RODOVIÁRIOS}

A RBV tem como premissa a identificação de recursos como elementos essências para a definição da estratégia e obtenção de vantagem competitiva das organizações. Conforme Wernerfelt (1984), a ideia da organização como um amplo conjunto de recursos remonta ao trabalho seminal de Penrose (1959). Sob essa perspectiva, Wilk e Fensterseifer (2003) afirmam que cada empresa pode ser vista como uma coleção única de recursos e capacidades, cuja forma de combinação e uso depende de sua administração.

Para Barney (2001), a RBV tem emergido como uma teoria promissora para analisar os recursos 
Uma maneira mais abrangente para categorizar os recursos é classificá-los como recursos tangíveis ou intangíveis, forma esta amplamente reconhecida na literatura de estratégia empresarial (GOHR et. al., 2011).

a) recursos tangíveis - São aqueles recursos que podem ser observados e avaliados com maior clareza, como é o caso de recursos físicos, sistemas de distribuição, invenções patenteadas, economias de escala, dentre outros (WILK; FENSTERSEIFER, 2003; MALAFAIA, 2007);

b) recursos intangíveis - São mais difíceis de identificar e quantificar e, normalmente, incluem recursos como reputação da empresa, imagem da marca, potencial de recursos humanos, conhecimento e cultura organizacionais, capacidade de aprendizagem, aquisição e gestão de tecnologias, know how, dentre outros. (TEECE; PISANO; SHUEN, 1997; WILK; FENSTERSEIFER, 2003; GRANT, 1991).

O desempenho superior de uma empresa é sustentável quando ela tem recursos capazes de lhe render resultados extraordinários (BRITO; VASCONCELOS, 2004). Malafaia (2007) explica que a investigação dos determinantes de uma vantagem competitiva sustentável está,em grande medida, baseada na Teoria Econômica.

\section{Os livros clássicos de economia} dizem-nos que os recursos mais valiosos têm uma oferta menor que a procura, e por isso são raros, podendo originar uns retornos diferentes, que se encontram relacionados com o fato do recurso ser raro e valioso. Isto é denominado de renda (ganhos maiores do que o ponto crítico caso a sua existência não provoque o aparecimento de novos concorrentes). Quando por alguma razão é impossível ou demasiado caro imitar o recurso ou substituí-lo por outro recurso que possa realizar as mesmas tarefas, a renda proveniente desse recurso pode ter longa duração. (MALAFAIA, 2007, p. 48).
Percebe-se, Portanto, Que

SOB A PERSPECTIVA DA RBV,

A VANTAGEM COMPETITIVA,

MEDIDA COMO RENTABILIDADE

ECONÔMICA, PODE SER DERIVA-

DA DE RECURSOS ESTRATÉGICOS

RAROS, VALIOSOS, DIFÍCEIS DE

SEREM COPIADOS OU SUBSTITU-

ÍDOS (BARNEY; HESTERLY,

2011).

Considerando o escopo da RBV, surge o desafio de reconhecer um modo eficaz para identificar esses recursos que contribuirão na criação de vantagem competitiva para as organizações. Faz-se necessária a utilização de um ferramental que possa estabelecer diretrizes para auxiliar na identificação e avaliação desses recursos na prática (BARNEY; HESTERLY, 2011).

A partir dessa constatação, os autores Barney e Hesterly (2011) desenvolveram um modelo denominado VRIO, sigla para as palavras Valor, Raridade, Imitabilidade e Organização. Este modelo tem o propósito ser uma ferramenta para analisar todos os recursos de uma empresa e também o potencial de cada um deles para gerar vantagem competitiva.As questões-chave para cada atributo do modelo são demonstradas no Quadro 2. 


\begin{tabular}{|c|l|}
\hline VRIO & \multicolumn{1}{c|}{ QUESTÕES CHAVE } \\
\hline Valor & $\begin{array}{l}\text { O recurso permite que a empresa explore uma oportunidade ambiental ou } \\
\text { neutralize uma ameaça? }\end{array}$ \\
\hline Raridade & $\begin{array}{l}\text { Orecurso é controlado atualmente apenas por um pequeno número de empresas } \\
\text { concorrentes? }\end{array}$ \\
\hline Imitabilidade & $\begin{array}{l}\text { As empresas sem o recurso enfrentam uma desvantagem de custo para obtê-lo } \\
\text { ou desenvolvê-lo? }\end{array}$ \\
\hline Organização & $\begin{array}{l}\text { As outras políticas e os procedimentos da empresa estão organizados para dar } \\
\text { suporte à exploração de seus recursos valiosos, raros e custosos para imitar? }\end{array}$ \\
\hline
\end{tabular}

Fonte: Barney e Hesterly (2011)

Barney (2001) afirma que recursos que são raros, valiosos, difíceis de imitar e de substituir, podem produzir vantagens competitivas sustentáveis. Portanto, raridade e valor são necessários, mas não suficientes para obter vantagens competitivas.Do mesmo modo, a não-imitação, não-substituição e não-transferência são necessárias, mas também não são suficientes para sustentar uma vantagem competitiva. Na verdade, a questão central da RBV é a maneira pela qual as empresas diferem e como elas conseguem alcançar e sustentar vantagens competitivas por meio da exploração de seus recursos.

c) aquestãodoValor-Se o recurso permitir que a empresa explore uma oportunidade ou neutralize uma ameaça, esta pode desenvolver uma força organizacional e uma paridade competitiva, desde que, além de manter recursos valiosos, a empresa saiba explorá-los. Um recurso é considerado valioso na medida em que ele melhora a eficácia e/ou a eficiência da empresa (RUNGTUSANATHAM et al., 2003). Uma forma de identificar recursos valiosos é analisando a cadeia de valor de uma organização, pois cada etapa da cadeia requer a aplicação e a integração de diferentes recursos, e a análise da cadeia incentiva os gestores a pensarem de forma desagregada nos recursos da organização (BARNEY; HESTERLY, 2011);

d) a questão da Raridade - Para proporcionar vantagem competitiva e uma força distintiva, um recurso, além de ser valioso precisa ser raro, de modo que ao exercer controle sobre ele, a empresa está explorando uma desvantagem dos concorrentes (RUNGTUSANATHAM et al., 2003). Portanto, a organização deve explorar recursos que sejam considerados valiosos e raros;

e) a questão da Imitabilidade - Para ser uma fonte de vantagem competitiva e uma força de distinção sustentável, um recurso, além de ser valioso, raro e explorado pela empresa, deve ser difícil de ser copiado. Para tanto, a empresa precisa 
criar mecanismos que tornem a imitação custosa,como por exemplo, o desenvolvimento de:(i) condições históricas únicas, que permitam vantagens de pioneirismo; (ii) ambiguidade causal, ou seja, quando os concorrentes não sabem o que está por trás de determinada vantagem competitiva; (iii) complexidade social, isto é, quando a vantagem competitiva de uma empresa é proveniente de relacionamentos interpessoais, confiança, cultura e outros recursos sociais; e (iv) patentes, que garantem o direito de propriedade sobre um recurso (PORTER, 1985). Segundo Malafaia (2007), pode ser muito difícil, se não impossível,imitar alguns recursos, não só pelos custos de transação e de transferência envolvidos, mas também porque, muitas vezes, esses ativos possuem certa dose de conhecimento tácito;

f) a questão da Organização - Para aproveitar o máximo de seus recursos, a empresa deve explorá-los e organizá-los. Para isso, é necessário desenvolver uma estrutura formal de reporte, controles gerenciais formais e informais, e políticas de remuneração que criem incentivos para que os funcionários sigam determinados padrões de comportamento. Cabe destacar que a organização atua como um fator de ajuste no modelo VRIO, pois não basta que ela tenha recursos valiosos e/ou raros e/ou difíceis de serem copiados. Necessariamente, a empresa precisa explorar o potencial desses recursos para gerar vantagens competitivas sustentáveis (BARNEY; HESTERLY, 2011).
Em consonância com o objetivo deste estudo, foi realizada uma pesquisa empírica que permitiu verificar os recursos estratégicos de novas plantas industriais de duas empresas do setor rodoviário, e se os recursos dessas empresas proporcionam vantagem competitiva sustentável. Feitas as análises individuais de cada empresa, procurou-se traçar um paralelo entre os achados nas duas organizações. Na sequência, serão apresentados os procedimentos metodológicos que conduziram o desenvolvimento desta pesquisa.

\subsection{Procedimentos Metodológicos}

A pesquisa que originou este artigo se propôs a analisar (i) se a decisão tomada por duas empresas líderes do setor rodoviário de instalarem fábricas fora do estado do Rio Grande do Sul contribuirá para criação de vantagem competitiva e (ii) estabelecer uma análise complementar dos resultados observados nas duas organizações. Os conceitos da Visão Baseada em Recursos não eram amplamente utilizados pelas empresas estudadas para montar suas estratégias, tampouco o método VRIO.

Por questões de sigilo, os nomes das empresas que foram objeto de estudo não serão citados neste artigo, identificando-as como empresa Alfa e empresa Beta.As organizações estudadas foram escolhidas pelo papel de liderança em seu segmento; por atuarem no mesmo setor, compartilhando, em grande parte, da mesma realidade de mercado; e pela relevância econômica e social que representam para a região serrana do Rio Grande do Sul. 
Para concretizar essa investigação, de caráter qualitativo e exploratório, utilizou-se o método de estudo de caso, que se constitui em uma abordagem ideal quando se deseja um entendimento mais profundo sobre os objetos pesquisados (YIN,1994). O estudo envolveu pesquisa bibliográfica sobre o tema da RBV e, visando uma análise mais detalhada sobre a questão dos recursos estratégicos nas empresas pesquisadas, foram realizadas entrevistas semiestruturadas, com perguntas abertas ao gerente de produção de cada uma das empresas, responsáveis pelo projeto e gestão das novas fábricas. Cada entrevista teve duração aproximada de uma hora, e as respostas dos gerentes foram transcritas, categorizadas e analisadas, tendo como base as classificações do modelo VRIO apontadas por Barneye Hesterly (2011).A análise documental e a observação passiva foram feitas em paralelo às entrevistas. $\mathrm{O}$ quadro 3 mostra as técnicas de coleta de dados utilizadas nessa pesquisa e suas finalidades.

Quadro 3: Técnicas de coleta de dados adotadas na pesquisa

\begin{tabular}{|c|c|c|}
\hline FASE & TÉCNICA & FINALIDADE \\
\hline \multirow[t]{2}{*}{ I } & \multirow[t]{2}{*}{ Revisão bibliográfica } & $\begin{array}{l}\text { Identificar na literatura autores que discutem a importância } \\
\text { dos recursos para a vantagem competitiva, assim como } \\
\text { métodos para avaliação de recursos. }\end{array}$ \\
\hline & & Apoiar a realização da pesquisa de campo. \\
\hline \multirow{3}{*}{ II } & Entrevista semiestruturada & $\begin{array}{l}\text { Identificar recursos valiosos, raros, difíceis de serem copiados } \\
\text { pela concorrência. }\end{array}$ \\
\hline & Observação passiva & \multirow{2}{*}{$\begin{array}{l}\text { Verificar, por meio do modelo VRIO, se os recursos } \\
\text { identificados contribuem para a vantagem competitiva da } \\
\text { organização estudada. }\end{array}$} \\
\hline & Análise documental & \\
\hline
\end{tabular}

Fonte: Gohr et al. (2011)

Para identificar os recursos estratégicos de cada organização, foi utilizada a tipologia proposta por Barney e Hesterly (2011), que os classifica em recursos financeiros, físicos, individuais e organizacionais. $\mathrm{Na}$ sequência, os recursos foram ponderados de acordo com o Modelo VRIO, avaliando-se cada um deles de acordo com ao seu valor, raridade, imitabilidade e organização. A proposta desenvolvida por Barneye Hesterly (2011) para avaliação dos recursosé apresentada no Quadro 4. 


\begin{tabular}{|l|l|l|l|l|l|}
\hline \multicolumn{5}{|c|}{ UM RECURSO É: } \\
\hline Valioso? & Raro? & $\begin{array}{c}\text { Custoso de } \\
\text { imitar? }\end{array}$ & Explorado? & Implicações competitivas & Força/Fraqueza \\
\hline Não & Não & Não & Não & Desvantagem competitiva & Fraqueza \\
\hline Sim & Não & Não & Sim & Paridade competitiva & Força \\
\hline Sim & Sim & Não & Sim & $\begin{array}{l}\text { Vantagem competitiva } \\
\text { temporária }\end{array}$ & Força distintiva \\
\hline $\operatorname{Sim}$ & Sim & Sim & Sim & $\begin{array}{l}\text { Vantagem competitiva } \\
\text { sustentável }\end{array}$ & $\begin{array}{l}\text { Força distintiva } \\
\text { sustentável }\end{array}$ \\
\hline
\end{tabular}

Fonte: Barney e Hesterly (2011)

A avaliação dos recursos, segundo a classificação VRIO, possibilitou aidentificação se os recursos das empresas podem ou não gerar vantagem competitiva e se colaboram para a criação da força ou da fraqueza organizacional. A análise das informações aconteceu por meio de análise de conteúdo que, segundo Azevedo (2008), proporciona a descrição objetiva e sistemática do conteúdo presente nos dados coletados.

\subsection{Características do Setor Rodoviário}

As primeiras indústrias do setor de veículos rebocados surgiram no início dos anos 50. Esse setor congrega mais de mil empresas de pequeno, médio e grande porte, predominantemente familiares, responsáveis pela fabricação de implementos rodoviários com diversas configurações e perfis. Desde o início, as indústrias do setor de implementos rodoviários tiveram que fabricar os seus produtos, observando as características da malha viária brasileira, que incluem estradas não pavimentadas ou em condições não ideais de trafegabilidade (SDPI, 2012).

Além disso, a participação dos modais rodoviário, ferroviário e hidroviário no transporte de cargas brasileiro é significativamente diferente daquela encontrada em outros países de dimensões continentais. No Brasil, existe uma grande concentração de transporte de cargas no modal rodoviário. Normalmente, países de grande extensão territorialutilizam mais intensivamente o modal ferroviário (SDPI, 2012).

O crescimento do setor primário, indústria, comércio e prestação de serviços impactam o desenvolvimento do setor de veículos rodoviários. A indústria de implementos rodoviários desenvolve produtos acessórios e complementares ao caminhão, dandolhe uma função no transporte de cargas. Essa indústria produz veículos rebocados, reboques, semirreboques e superestruturas, e acessórios, como caçambas e carrocerias sobre chassi, eixos auxiliares e quinta-roda. 
A versatilidade desse setor industrial permite que se tenham todas as variedades de equipamentos, tanto sob o aspecto de dimensões, como especificações das mais sofisticadas, qualidade, durabilidade, etc. (SDPI, 2012).

O Brasil encontra-se entre os maiores produtores mundiais de auto veículos e atingiu uma produção de 3,4 milhões de veículos em 2011. O país também é um dos maiores mercados mundiais de veículos rebocados. As exportações de veículos rebocados ainda representam pouco no faturamento das empresas do setor. Esse fato deve-se principalmente às características de customização que cada mercado exige, em função de suas peculiaridades de legislação, e às dificuldades logísticas associadas ao transporte dos implementos rodoviários. Uma alternativa para contornar o problema das características próprias que cada mercado demanda é a realização de exportações por meio do sistema de CKD. Atualmente, os principais mercados externos das empresas brasileiras de implementos rodoviários são o Mercosul, a África e o Oriente Médio (SDPI, 2012).

Segundo informações disponibilizadas pela empresa Alfa,ela faz parte de um conglomerado de 11 empresas, atuantes nos setores de autopeças, serviços e implementos rodoferroviários. A receita líquida da empresa Alfa foi de $\mathrm{R} \$$ 3,9 bilhões no período compreendido entre janeiro e novembro de 2013 e conta com 4.127 funcionários. Um dos objetivos da empresa é dobrar seu faturamento, sendo que a produção de veículos frigoríficos no estado de santa Catarina é parte de sua estratégia para atingir esse objetivo.
A empresa Beta, também alvo desse estudo, atualmente conta com três unidades fabris em operação: duas fábricas em Caxias do Sul(RS) e uma em Farroupilha (RS), além de uma planta industrial desativada no estado de São Paulo, onde a empresa tinha operações no passado e que agora pretende reativar, adaptando a estrutura lá existente para produzir veículos frigoríficos. A empresa Beta atua nos setores de autopeças, serviços e implementos rodoferroviários, contando com 1.800 funcionários ativos e uma rede de 57 distribuidores e assistências técnicas que atua no Brasil, com mais de $10 \mathrm{mil}$ clientes ativos. Atualmente, a empresa exporta para 16 países, distribuídos na América Latina, África e Emirados Árabes.

Para a reativação da unidade em São Paulo, a empresa Beta utilizará o recurso existente e que foi desativado no ano de 2012 por decisões estratégicas. Para a produção inicial, não existe a necessidade de investimentos que impliquem ampliação dos recursos e do parque fabril, que estima o volume de 1.200 unidades para o ano de 2014.

\subsection{Análise de Dados}

Na sequência, cada recurso observado no desenvolvimento da pesquisa empírica é apresentado detalhadamente, de acordo com cada empresa estudada.

\subsubsection{Recursos Identificados na Empresa Alfa}

Os recursos identificados junto à empresa Alfa foram classificados como financeiros, físicos, individuais e organizacionais, conforme propuseram Gohr et tal (2011), e estão apresentados no quadro 5. 


\begin{tabular}{|c|l|}
\hline RECURSOS & \multicolumn{1}{|c|}{ CARACTERÍSTICAS } \\
\hline Financeiros & Ativos e capital de giro financiado com recursos próprios e do BRDE. \\
\hline Físicos & $\begin{array}{l}\text { Alta tecnologia de manufatura, com máquina de última geração; localização } \\
\text { geográfica privilegiada, na área com o maior consumo de seus produtos. }\end{array}$ \\
\hline Individuais & $\begin{array}{l}\text { Com quase } 70 \text { anos de experiência, a empresa domina conhecimentos nos } \\
\text { processos de manufatura; o modelo de gestão de pessoas alavanca o resultados } \\
\text { das empresas do grupo e será replicado na nova fábrica. }\end{array}$ \\
\hline Organizacionais & $\begin{array}{l}\text { A marca da empresa é sólida e reconhecida em todo Brasil; como já aconteceu } \\
\text { no passado, a empresa tem experiência em aquisições. }\end{array}$ \\
\hline
\end{tabular}

Fonte: Adaptado de Barney e Hesterly (2011)

a) Recursos financeiros: A nova empresa foi adquirida e passa por adequações financiadas por recursos próprios e financiamento do Banco Regional de Desenvolvimento do Extremo Sul (BRDE). Sendo a maior empresa rodoferroviária do Brasil, com 30\% do mercado nacional, a Alfa tem disponibilidade de capital próprio para aquisições e ampliações.

b) Recursos físicos: A empresa possui um equipamento de alta tecnologia que permite a injeção do produto em módulos, minimizando a ocorrência de problemas de qualidade. A matéria-prima utilizada pela companhia provém de diversos países do mundo, porém primariamente do estado do Rio Grande do Sul.A matriz de fornecedores de matérias-primas paulatinamente migrará para Santa Catarina, aproveitando-se dos incentivos fiscais deste estado. Como 80\% das vendas dos produtos da empresa são feitas para Santa Catarina, a presença nesse estado cria vantagem em relação à localização geográfica, uma vez que a aproxima de seu maior mercado consumidor. $\mathrm{O}$ novo empreendimento no estado catarinense tem $11.800 \mathrm{~m}^{2}$ de área construída e $100.000 \mathrm{~m}^{2}$ de área total, o que auxiliará na futura expansão da unidade, assim que necessário for.

c) Recursos individuais: A companhia conta com 69 funcionários para uma produção de 0,5 produto por dia. Há planos para ampliação da produção, visando aumento para 20 produtos por dia e a contratação de mais 134 funcionários, trabalhando em três turnos. Os processos de manufatura são dominados e melhorados pela empresa há décadas, experiência que facilita o desenvolvimento de novas tecnologias.

d) Recursos organizacionais:Para expandir os negócios, as aquisições são uma alternativa rápida e eficiente. Como a empresa já participa de joint-ventures e adquiriu outras empresas no passado, tem experiência nesse tipo de ampliação. 


\subsubsection{Recursos Identificados na Empresa Beta}

Nesta seção, são expostos os recursos da empresa Beta, conforme sintetiza o quadro 6.

Quadro 6: Identificação de recursos estratégicos da empresa Beta

\begin{tabular}{|c|l|}
\hline RECURSOS & \multicolumn{1}{c|}{ CARACTERÍSTICAS } \\
\hline Financeiros & Incentivos fiscais e utilização de recursos próprios \\
\hline Físicos & $\begin{array}{l}\text { Vantagem logística, centro de dobra, conjunto de chassi robusto, teto com chapas } \\
\text { inteiriças }\end{array}$ \\
\hline Individuais & Matéria-prima disponível no estado onde a planta futura será instalada \\
\hline Organizacionais & Treinamento e cultura organizacional \\
\hline
\end{tabular}

Fonte: Adaptado de Barney e Hesterly (2011)

a) Recursos financeiros: Como a planta fabril no estado de São Paulo já existe, será agora remodelada a fim de comportar a produção de furgões frigoríficos. Para efetuar essa adaptação de estrutura, a empresa Beta conta com os incentivos fiscais do estado paulistano, bem como dispõe de recursos próprios, o que reduz o nível de endividamento da companhia e proporciona um retorno sobre o investimento de forma mais rápida.

b) Recursos físicos: $O$ conjunto de chassis robusto, o processo de produção com capas inteiriças e o centro de dobra altamente tecnológico conferem confiabilidade ao produto da empresa Beta. Além disso, a maioria dos furgões frigoríficos produzidos pela empresa serão vendidos para a região onde a unidade estará instalada, permitindo uma vantagem competitiva que se torna custosa para os concorrentes copiarem. c) Recursosindividuais: Aempresa possui uma ampla matriz de fornecedores no estado onde vai instalar sua operação, garantindo que não haverá escassez de matéria-prima. Essa disponibilidade se traduz em agilidade de atendimento das necessidades de suprimento.

d) Recursos organizacionais: Como a empresa verificou que a mão-de-obra qualificada é escassa no estado paulistano, pretende aproveitar esse fato para treinar seus futuros funcionários. Dessa forma, transformará essa fraqueza estratégica inicial em uma vantagem competitiva sustentável, uma vez que terá a oportunidade de iniciar seus funcionários na sua cultura organizacional. 


\subsection{Discussão dos Resultados}

Depois que os recursos estratégicos das empresas Alfa e Beta foram identificados, eles foram avaliados de acordo com o modelo VRIO (BARNEY; HESTERLY, 2011), analisando-se o valor, a raridade, a imitabilidade e a organização dos referidos recursos. Essa avaliação está exposta no quadro 7. Por meio dessa análise, foi possível identificar quais as vantagens competitivas dos recursos que as empresas estudadas dispõem. A análise ainda permitiu checar se os recursos contribuíram para uma força ou fraqueza da organização, servindo como um possível alerta às empresas sobre quais itens poderiam ser enfocados e trabalhados prioritariamente.

Quadro 7: Avaliação dos recursos estratégicos da empresa Alfa

\begin{tabular}{|c|c|c|c|c|c|c|}
\hline \multicolumn{7}{|c|}{ RECURSOS FINANCEIROS } \\
\hline RECURSO & Valor & Raridade & Imitabilidade & Organização & $\begin{array}{l}\text { Implicações } \\
\text { Competitivas }\end{array}$ & Força/ Fraqueza \\
\hline Capital próprio & Sim & Sim & $\operatorname{Sim}$ & Sim & $\begin{array}{l}\text { Vantagem competitiva } \\
\text { sustentável }\end{array}$ & $\begin{array}{l}\text { Força distintiva e } \\
\text { sustentável }\end{array}$ \\
\hline $\begin{array}{l}\text { Acesso a } \\
\text { financiamento }\end{array}$ & Sim & Não & Não & Sim & Paridade competitiva & Força \\
\hline \multicolumn{7}{|c|}{ RECURSOS FÍSICOS } \\
\hline $\begin{array}{l}\text { Localização } \\
\text { geográfica }\end{array}$ & Sim & Não & $\operatorname{Sim}$ & Não & Paridade competitiva & Força \\
\hline $\begin{array}{l}\text { Tecnologia de } \\
\text { manufatura }\end{array}$ & Sim & Sim & Sim & Não & $\begin{array}{l}\text { Vantagem competitiva } \\
\text { temporária }\end{array}$ & Força distintiva \\
\hline \multicolumn{7}{|c|}{ RECURSOS INDIVIDUAIS } \\
\hline $\begin{array}{l}\text { Conhecimento do } \\
\text { negócio }\end{array}$ & Sim & Não & Não & Sim & Paridade competitiva & Força \\
\hline Gestão das pessoas & Sim & Não & Não & Sim & Paridade competitiva & Força \\
\hline \multicolumn{7}{|c|}{ RECURSOS ORGANIZACIONAIS } \\
\hline Marca & Sim & Sim & $\operatorname{Sim}$ & Sim & $\begin{array}{l}\text { Vantagem competitiva } \\
\text { sustentável }\end{array}$ & $\begin{array}{l}\text { Força distintiva e } \\
\text { sustentável }\end{array}$ \\
\hline $\begin{array}{l}\text { Habilidade em } \\
\text { aquisições }\end{array}$ & Sim & Sim & $\operatorname{Sim}$ & Sim & $\begin{array}{l}\text { Vantagem competitiva } \\
\text { sustentável }\end{array}$ & $\begin{array}{l}\text { Força distintiva e } \\
\text { sustentável }\end{array}$ \\
\hline
\end{tabular}

Fonte: Dos autores (2014)

Os dados coletados apresentaram oito recursos, sendo que somente três deles proporcionam à empresa uma vantagem competitiva e uma força distintiva sustentável, quais sejam: capital próprio, marca e habilidade em aquisições. Dessa forma, esses recursos são considerados valiosos e raros, uma vez que ajudam a empresa a neutralizar as ameaças e potencializam as oportunidades.

Atuando em seu setor com produtospremium, a pesquisa apontou que os recursos apresentados ajudam a empresa Alfa a se diferenciar dos concorrentes. Tal diferenciação cria uma barreira 
aos concorrentes para atingir os mesmos níveis de excelência nos produtos. O estudo demonstrou que a empresa tem grande capacidade produtiva e tecnologia de processo à frente de seus concorrentes, com a injeção dos produtos modularmente, o que dificulta a sua imitação.

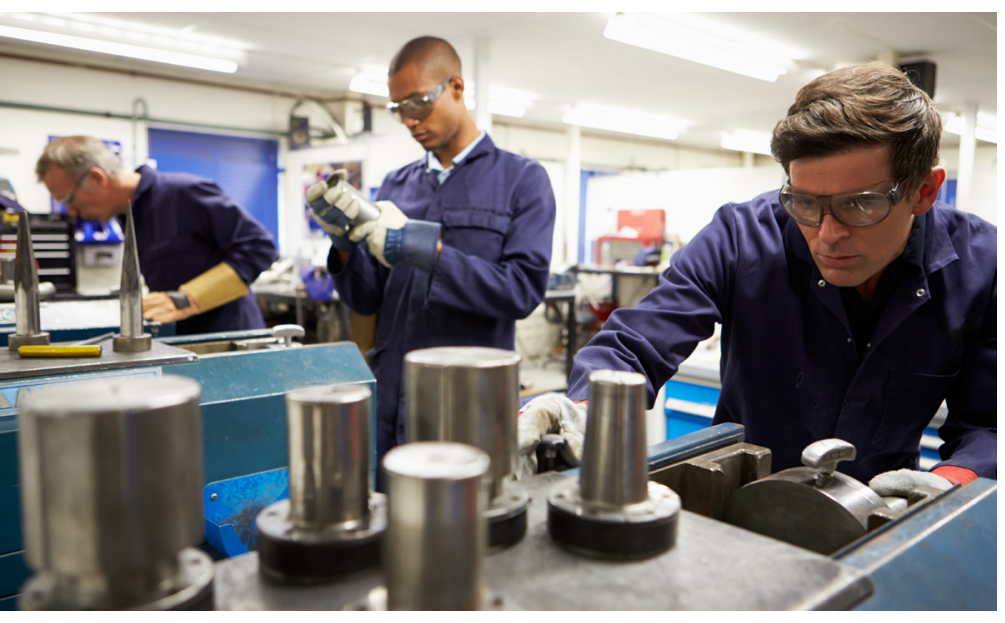

Com quase 70 anos de história e liderando seu segmento no Brasil, a Alfa é a quinta maior no mundo em seu campo de atuação, de acordo com monitoramento realizado pela empresa, e apresenta uma marca consolidada mundialmente. A empresa também conta com capital próprio, que permite aquisições e adequações de forma mais acelerada frente à concorrência. A experiência obtida com as aquisições no passado constitui um diferencial, pois é uma habilidade desenvolvida ao longo do tempo.
Esses recursos não estão disponíveis aos concorrentes da mesma forma que se apresentam para a empresa Alfa.

Embora os recursos mencionados gerem vantagem competitiva para a empresa, a tendência é que, com o passar do tempo, os concorrentes atinjam patamares semelhantes. Portanto, para manter um diferencial, a empresa investiu na aquisição do novo empreendimento no estado catarinense, que iniciou com expansão acentuada a fim de triplicar a produção dessa nova unidade fabril em um ano. Esse investimento aconteceu em consonância com a visão da empresa, de dobrar seu faturamento em um espaço de cinco anos.

Os recursos que geraram paridade competitiva e vantagem competitiva temporária também são explorados pela empresa, mas que não contribuem para fraqueza organizacional. $\mathrm{Na}$ busca do desenvolvimento contínuo, a empresa deve permanecer desenvolvendo seus outros recursos, com vistas à criação de barreiras aos concorrentes, alavancando seu resultado.

Com relação à empresa Beta, foi efetuada a análise de suas vantagens competitivas, a partir do quadro 8. 
Quadro 8: Avaliação dos recursos estratégicos da empresa Beta

\begin{tabular}{|c|c|c|c|c|c|c|}
\hline \multicolumn{7}{|c|}{ RECURSOS FINANCEIROS } \\
\hline RECURSO & Valor & Raridade & Imitabilidade & Organização & $\begin{array}{l}\text { Implicações } \\
\text { Competitivas }\end{array}$ & Força/ Fraqueza \\
\hline $\begin{array}{l}\text { Incentivos } \\
\text { Fiscais }\end{array}$ & Sim & Não & Sim & Sim & $\begin{array}{l}\text { Vantage m } \\
\text { competitiva } \\
\text { temporária }\end{array}$ & Força distintiva \\
\hline $\begin{array}{l}\text { Capital } \\
\text { próprio }\end{array}$ & $\operatorname{Sim}$ & Sim & Sim & Sim & $\begin{array}{l}\text { Va n ta g e m } \\
\text { competitiva } \\
\text { sustentável }\end{array}$ & $\begin{array}{l}\text { Força distintiva e } \\
\text { sustentável }\end{array}$ \\
\hline \multicolumn{7}{|c|}{ RECURSOS FÍSICOS } \\
\hline $\begin{array}{l}\text { Vantagem } \\
\text { logística }\end{array}$ & Sim & Sim & Sim & Sim & $\begin{array}{l}\text { Va n t a e m } \\
\text { competitiva } \\
\text { sustentável }\end{array}$ & $\begin{array}{l}\text { Força distintiva e } \\
\text { sustentável }\end{array}$ \\
\hline $\begin{array}{l}\text { Centro de } \\
\text { dobra }\end{array}$ & Sim & Sim & Sim & Sim & $\begin{array}{l}\text { Va n t a e m } \\
\text { competitiva } \\
\text { sustentável }\end{array}$ & $\begin{array}{l}\text { Força distintiva e } \\
\text { sustentável }\end{array}$ \\
\hline $\begin{array}{l}\text { Conjunto de } \\
\text { chassi robusto }\end{array}$ & Sim & Sim & Sim & Sim & $\begin{array}{l}\text { Va n t a e m } \\
\text { competitiva } \\
\text { sustentável }\end{array}$ & $\begin{array}{l}\text { Força distintiva e } \\
\text { sustentável }\end{array}$ \\
\hline $\begin{array}{l}\text { Teto com cha- } \\
\text { pas inteiriças }\end{array}$ & Sim & Sim & Sim & Sim & $\begin{array}{l}\text { Va n ta g e m } \\
\text { competitiva } \\
\text { sustentável }\end{array}$ & $\begin{array}{l}\text { Força distintiva e } \\
\text { sustentável }\end{array}$ \\
\hline \multicolumn{7}{|c|}{ RECURSOS INDIVIDUAIS } \\
\hline $\begin{array}{l}\text { Matéria- } \\
\text { prima } \\
\text { disponível } \\
\text { no estado e } \\
\text { região }\end{array}$ & Sim & Sim & Sim & Sim & $\begin{array}{l}\text { Va n t a e m } \\
\text { competitiva } \\
\text { sustentável }\end{array}$ & $\begin{array}{l}\text { Força distintiva e } \\
\text { sustentável }\end{array}$ \\
\hline \multicolumn{7}{|c|}{ RECURSOS ORGANIZACIONAIS } \\
\hline Mão-de-obra & Não & Não & Não & Sim & $\begin{array}{l}\text { Desvantagem } \\
\text { competitiva }\end{array}$ & Fraqueza \\
\hline $\begin{array}{l}\text { Treinamento } \\
\text { e cultura } \\
\text { organizacional }\end{array}$ & Sim & Sim & Sim & Sim & $\begin{array}{l}\text { Va n t a e m } \\
\text { competitiva } \\
\text { sustentável }\end{array}$ & $\begin{array}{l}\text { Força distintiva e } \\
\text { sustentável }\end{array}$ \\
\hline
\end{tabular}

Fonte: Dos autores (2014) 


\section{Os DADOS COLETADOS}

APRESENTARAM DEZ RECURSOS,

SENDO QUE SETE DELES

PROPORCIONAM À EMPRESA

BETA UMA VANTAGEM

COMPETITIVA E UMA FORÇA

DISTINTIVA SUSTENTÁVEL,

QUAIS SEJAM: A UTILIZAÇÃO DE

CAPITAL PRÓPRIO, A VANTAGEM

LOGÍSTICA, CENTRO DE

DOBRA, CONJUNTO DE CHASSIS

ROBUSTO, TETO COM CHAPAS

INTEIRIÇAS, MATÉRIA-PRIMA

DISPONÍVEL NO ESTADO E

REGIÃO, E O TREINAMENTO E A

CULTURA ORGANIZACIONAL.

Esses recursos são considerados valiosos e raros e auxiliam a empresa a ampliar as oportunidades e minimizar as ameaças.

O estudo demonstra que os recursos valiosos citados acima atuam como diferenciais para a empresa Beta em relação aos seus concorrentes. Tais diferenciais acabam por se tornar barreiras de entrada para os concorrentes. A empresa Beta tem acesso a capital próprio, o que também a diferencia de alguns concorrentes em termos disponibilidade de recursos.

A Beta planeja reativar sua planta industrial, remodelando-a para produção de furgões frigoríficos no estado de São Paulo. Essa região representa uma oportunidade de ampliação na participação do mercado,onde a empresa Betajá possui $3 \%$ no volume de vendas desse produto, oferecendo uma força distintiva e sustentável em relação aos seus concorrentes no que se refere à vantagem logística, proporcionada pela proximidade física ao mercado consumidor.

Com alta tecnologia, o centro de dobra da empresa Beta, dedicado à fabricação de peças para os furgões frigoríficos a serem produzidos, proporciona maior agilidade no processo, com maior qualidade. Ainda com relação à estrutura do produto, o teto de chapas inteiriças, aplicado em sua fabricação, aumenta a qualidade e robustez do produto, sendo de difícil imitação. Essa robustez também é encontrada nos chassis dos produtos da empresa Beta, auxiliando a empresa também como um diferencial competitivo.

O estado de São Paulo, onde a empresa Beta deseja reativar sua fábrica, para produção de furgões frigoríficos, ébem abastecida em termos de fornecedores de matérias-primas, o que se caracteriza como uma vantagem, uma vez que o risco de desabastecimento é minimizado.

Por tradição, a empresa investe em treinamento de seus funcionários, e esses treinamentos se traduzem em melhorias no trabalho, na qualidade de seus produtos e aumento de sua eficiência operacional.Em complemento, os treinamentos ministrados acabam por multiplicar a cultura da empresa, que durante 44 anos a auxiliou na obtenção de seus resultados.

Com a escassez de mão de obra no mercado metal mecânico em geral, o perfil de trabalhador é de pessoas que nunca trabalharam na indústria, e essas pessoas ainda não atentem aos padrões de desempenho que a empresa Beta deseja alcançar. Esse aspecto caracteriza o recurso organizacional da mão de obra como uma fraqueza, que deve ser trabalhada com atenção pela empresa em estudo. 


\section{CONSIDERAÇÕES FINAIS}

A pesquisa possibilitou a identificação de recursos que propiciam vantagem estratégica às empresas pesquisadas. Esses recursos podem conduzir as organizações a um direcionamento de foco estratégico, em que explorem mais intensa e efetivamente seus recursos valiosos, raros e difíceis de imitar.

Os resultados apresentados na pesquisa empírica demonstram que apenas um dos recursos identificados gera desvantagem competitiva, correspondente à escassez de mão de obra qualificada, conforme relato na empresa Beta.

Observando-se os

RESULTADOS DA PESQUISA

EMPÍRICA NAS DUAS

EMPRESAS, A PARTIR DA

TIPOLOGIA QUE CLASSIfICA OS

RECURSOS EM FINANCEIROS,

FÍSICOS, INDIVIDUAIS E

ORGANIZACIONAIS (BARNEY;

HESTERLY, 2011),

PERCEBE-SE A EMPRESA

Alfa APRESENTA MAIOR

VANTAGEM COMPETITIVA

DEVIDO A RECURSOS

ORGANIZACIONAIS, ENQUANTO

QUE, NA EMPRESA BETA, O

DIFERENCIAL CAPAZ DE CRIAR

VANTAGEM COMPETITIVA

PROVÉM PRINCIPALMENTE DE

RECURSOS FÍSICOS.
Portanto, em uma análise mais acurada dos resultados, observa-se que o que gera vantagem competitiva sustentável, no caso da empresa Alfa, diz respeito aos recursos organizacionais, vinculados à sua marca e habilidade em aquisições. Por serem recursos essencialmente intangíveis (GOHR et.al.,2011), eles são mais difíceis de quantificar, mas, por outro lado, também são de difícil imitação,já que estão vinculados ao conhecimento, know howe reputação da empresa. Essa constatação pode evidenciar o reconhecimento da empresa por parte dos seus clientes, como provedora de produtos de qualidade, assim como sua representatividade no âmbito empresarial.

Já na empresa Beta,destacam-se recursos tangíveis, que podem ser observados e avaliados com maior clareza (GOHR et. al., 2011), tal como a utilização de recursos próprios, a disponibilidade de matéria-prima e, principalmente, os recursos físicos, vinculados à vantagem logística, centro de dobra, conjunto de chassi robusto e teto com chapas inteiriças. Esses recursos caracterizam a empresa Beta como provedora de tecnologias inovadoras e reconhecida robustez de seus produtos.

Diante do exposto, esta pesquisa procurou contribuir para a teoria sobre o tema, com a disseminação da utilização do modelo VRIO, proposto por Barney e Hesterly (2011), como instrumento de diagnóstico e de melhoria contínua para as empresas, auxiliando-as a potencializar seus resultados por meio da melhor utilização de seus recursos. 
O estudo de caso múltiplo amplia a aplicação desse tipo de pesquisa para a academia. Diante dessa perspectiva, o desafio está em explorar os resultados que aparecem na pesquisa, criando práticas que possam atender ao desenvolvimento da empresa por meio dos recursos que se destacam.

A pesquisa aponta ainda a relevância acadêmica e econômica do tema, ao mostrar quão importante é a identificação das vantagens competitivas e seu papel no desempenho de empresas pertencentes ao setor automobilístico, o qual exerce papel preponderante na indústria nacional.Estudos como este trazem à tona elementos essenciais à tomada de decisão empresarial,com respaldo teórico e fundamentação nos conceitos desenvolvidos pela RBV. Os avanços nesse campo teórico podem ser possíveis a partir da aplicação, se possível constante, entre teoria e prática, como este artigo procura ilustrar.

As análises feitas derivaram do emprego de um método consistente de identificação das vantagens competitivas das empresas estudadas, que possibilita o levantamento de prioridades e do caminho a seguir para a exploração dessas vantagens. Assim, a maneira como as vantagens competitivas se apresentam e interagem indica a necessidade que as organizações, cada vez mais, têm de trabalharem no sentido de valorizar os recursos que as compõem. Estes recursos são os que detêm o poder de gerar competências e de transformar vantagens em diferencial competitivo e, por consequência, interferir no desempenho dessas organizações.

Para estudos futuros, sugere-se um trabalho longitudinal para verificar como as vantagens competitivas dessas empresas se comportaram com o passar do tempo, e se realmente as vantagens apontadas por esse estudo como diferenciais de vantagem competitiva sustentável e força distintiva se manterão ao longo dos anos. Embora as empresas Alfa e Beta representem aproximadamente $70 \%$ do mercado nacional de implementos rodoviários, outra sugestão de trabalho futuro é o estudo das vantagens competitivas, utilizando-se o modelo VRIO no setor rodoviário como um todo. 


\section{IDENTIFICATION}

OF STRATEGIC

RESOURCES

GENERATORS OF

COMPETITIVE

ADVANTAGE: A CASE STUDY IN THE ROAD SECTOR

\begin{abstract}
Although the strategic positioning approach is the mostreferenced with respect to competitive advantage, authors point out to the Resource Based View, that values internal resources - physical, financial, individual, organizational. The VRIO model contributes to identify these resources, analyzing them according to theirvalue, rarity, inimitability and organization. By using the VRIO model, this case study aimed to identify and to analyze whethernewindustrial plants resources of two rail-roadequipment sectorcompanies contribute to their competitive advantage. It was found that, in one of the companies, the advantage comes from organizational resources, while in another, comes from physical resources.
\end{abstract}

Keywords: Strategic Resources. Competitive Advantage. Road Sector.

\section{REFERÊNCIAS}

ANFIR - Associação Nacional dos Fabricantes de Implementos Rodoviários. Emplacamento do setor. Disponível em: <http://www.anfir.org.br/ downloads/desempenho_jan_dez._2013.pdf〉. Acesso em 20 de jan. 2014.

AZEVEDO, C. A. M.; AZEVEDO, A. G.

Metodologia científica: contributos práticos para a elaboração de trabalhos acadêmicos. 9. ed. Lisboa: Universidade Católica, 2008.

BARNEY,J. B. Is the resource based "view" a useful perspective for strategic management research? Yes. Academy of Management Review, v. 25, n. 1, p. 41-56, 2001.

BARNEY, J. Firm resources and sustained competitive advantage. Journal of Management, $v$. 17, n. 1, p. 99-120, 1991.

BARNEY,J. B.; Hesterly, W. S. Administração estratégica e vantagem competitiva. São Paulo: Pearson Prentice Hall, 2011.

BRITO, L. A. L.; VASCONCELOS, F. C. de. A heteroge $\neg$ neidade do desempenho, suas causas e o conceito de vantagem competitiva: proposta de uma métrica. Revista de Administração Contemporânea, Edição Especial, p. 107-129, 2004.

FLEURY, Maria Tereza Leme; FLEURY, Afonso Carlos Correa. Alinhando estratégia e competências. Rev. adm. empres., São Paulo, v. 44, n. 1, Mar. 2004.

FOSS, N. J. Knowledge-based approaches to the theory of the firm: Some critical comments. Organization Science, v. 7, n. 5, p. 470 - 476, 1996. 
GOHR, C. F.; SANTOS, L. C.; BURIN, C. B.; MARQUES, S. M.; ARAI, R. M. Recursos estratégicos e vantagem competitiva: aplicação do modelo VRIO em uma organização do setor sucroalcooleiro. Revista Gestão Organizacional, v. 4, n. 1, 60-71, 2011.

GRANT, R. M. The resource-based theory of competitive advantage: implications for strategy formulation. California Management Review, v. 33, n. 3, p.114-135, 1991.

JOIA, L. A.; FERREIRA, S. Modelo de negócios: construto real ou metáfora de estratégia? Cadernos Ebape. BR, v.3, n.4, Dez. 2005.

LOBATO, D. M. Estratégia das empresas. 9 ed. Rio de Janeiro: FGV Editora, 2003.

MALAFAIA, Guilherme Cunha. As convenções sociais de qualidade como suporte à configuração de sistemas agroalimentares locais competitivos: um estudo cross country na pecuária de corte, 2007. Tese de Doutorado em Agronegócios, Universidade Federal do Rio Grande do Sul, Porto Alegre.

PORTER, M. E. (ed.) Estratégia: a busca da vantagem competitiva. Rio de Janeiro: Campus, 1980.

PORTER, M. E. Competitive Advantage: creating and sustaining superior performance. New York: The Free Press, 1985.

PORTER, M. E. What Is Strategy? Harvard Business Review, p. 74-91, Nov-Dec. 1996.

PRAHALAD, C. K.; HAMEL, G. The core competence of the corporation. Harvard Business Review, v. 68, n. 3, p. 79-91, 1990.

RUNGTUSANATHAM, M.; SALVADOR, F.; FORZA, C.; CHOI, T.Y. Supply-chain linkages and operational performance: A resource-based-view perspective. International Journal of Operations \& Production Management, v. 23, n. 9, p. 1084-1099, 2003.
SDPI - Secretaria de Desenvolvimento e Promoção do Investimento. (2012). Programa Setorial Automotivo e Implementos Rodoviários 20122014. Disponível em: <http://www.sdpi.rs.gov.br/ upload/20120328150854programa_setorial automotivo_e_implementos_rodoviarios.pdf $>$. Acesso em 19 de fev. 2014.

SIMEFRE - Sindicato Interestadual da Indústria de Materiais e Equipamentos Ferroviários e Rodoviários. Indústria de implementos produz $4,92 \%$ a mais que em 2012. Disponível em <http://www.simefre.org.br/ Data/Release-Implementos.pdf $>$. Acesso em 18 de fev. 2014.

TEECE, D. J.; PISANO, G.; SHUEN, A. Dynamic capabilities and strategic management. Strategic Management Journal, v. 18, n. 7, p. 509-533, 1997.

VASCONCELOS, F. C.; CYRINO, A. B.

Vantagem competitiva: os modelos teóricos atuais e a convergência entre a estratégia e a teoria organizacional. RAE - Revista de Administração de Empresas,v. 40, n. 4, p. 20-37, 2000.

WERNERFELT, B. A resource-based view of the firm. Strategic Management Journal, v. 5, n. 2, p.171180, 1984

WILK, Eduardo de Oliveira; FENSTERSEIFER, Jaime Evaldo. Use of resource-based view in industrial cluster strategic analysis. International Journal of Operations \& Production Management, v. 23, n. 9, p. 995-1009, 2003.

YIN, R. K. Case study research: design and methods. 2. ed. Sage: Thousand Oaks, 1994.

Data de recebimento: 26/01/2015

Data de aprovação: 29/07/2016 


\section{SOBRE OS AUTORES}

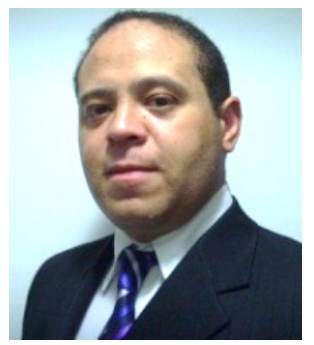

\section{Gregorio Bastos Neto}

Mestre em Administração de Empresas com ênfase em Estratégia e Gestão da Produção pela Universidade de Caxias do Sul (2015) e graduação em Automatização Industrial pela Universidade de Caxias do Sul (2007). Atualmente éprofessor dos cursos de Administração de Empresas e Engenharia de Produção, bem como no MBA em Engenharia de Produção. Atua na indústria na área de Engenharia de Produção trabalhando com Sistemas de Produção, Kaizen, Troca Rápida de Ferramentas (TRF), Gestão do Posto de Trabalho (GPT), 5 Sensos (5S's), Mapeamento de Fluxo de Valor (VSM) e Trabalho Padrão.

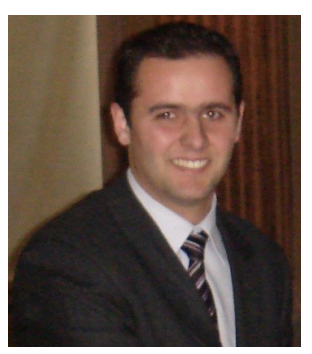

\section{Isaias Ricardo Carraro}

Mestrado em Administração - UCS (2016). MBA em Gestão Estratégica de Produção-UCS(2013).MBA em Gestão de Operações Logísticas e Supply Chain - Faculdade da Serra Gaúcha-FSG (2012).Graduadoem Administração de Empresas-UCS (2010).Diplomado em Logística Integral - Pontifícia Universidad Javeriana (Bogotá - Colômbia - 2006). Diplomado em Gerência de Projetos - Universidad de La Sabana (Bogotá Colômbia - 2004). Tradutor Público Juramentado e Intérprete Comercial nos idiomas Português/ Espanhol. Professor e Coordenador dos cursos de Graduação emLogística/Gestão Comercial/Gestão deRecursos Humanos na Faculdade daSerra Gaúcha - FSG (Caxias do Sul). Professor e Coordenador dos cursos Técnicos: Logística/Transações Imobiliárias no Instituto Cultural e Desportivo Mutirão.

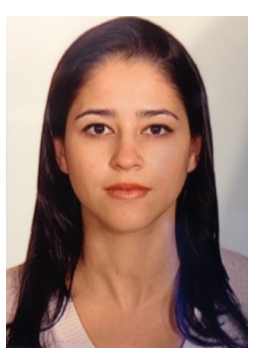

Simone Fonseca de Andrade

Mestre em Administração - UCS (2014), possui MBA em Comércio e Relações Internacionais pela UCS (2007),graduação em Comunicação SocialJornalismo pela UCS (2006) e graduação em Administração de Empresas - Comércio Exterior pela UCS (2009). Atualmente, é professora e coordenadora do Curso deGraduação em Comércio Internacional-CARVI/ UCS, lecionando também em outros cursos de Graduação e Pós-Graduação Lato Sensu. Atuou profissionalmente nas áreas de Câmbio e Comércio Internacional, Marketing e Comunicação. Sua atuação acadêmica e profissional está direcionada aos seguintes temas: Câmbio, Comércio Internacional, Finanças, Administração e Comunicação

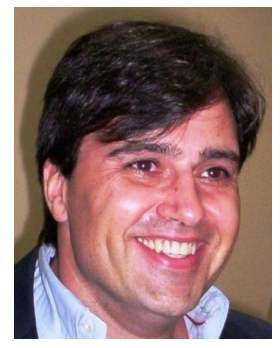

\section{Guilherme Cunha Malafaia}

Doutor em Agronegócios na Universidade Federal do Rio Grande do Sul-UFRGS (2008),Mestre em Economia Rural pela Universidade Federal de Viçosa - UFV (1998), com Graduação e Pós-Graduação em Administração de Empresas pela Universidade da Região da Campanha (1994; 1995). É pesquisador classe A da EMBRAPA, atuando no CNPGC. É consultor sênior do Banco Mundial e professor permanente do Programa de Pós-Graduação Stricto Sensu em Administração da Universidade de Caxias do Sul (Doutorado e Mestrado). É professor colaborador do: PPG Stricto Sensu em Agronegócios da Universidade Federal da Grande Dourados (Mestrado); PPG em Gestāo e Produçāo 
Agroindustrial da Universidade Anhanguera/ Uniderp(Mestrado);PPGAdaUniversidadeFederal do Mato Grosso do Sul (Doutorado).

\section{***}

